\title{
Qualidade do leite de vacas criadas no sistema silvipastoril no Vale do Cauca, Colômbia ${ }^{1}$
}

\author{
Carmen A.D. Bolaños ${ }^{2,3}$, José C.F. Pantoja ${ }^{4}$, Ana C. Alves ${ }^{3}$, Rafaela M. Risseti ${ }^{3}$, \\ Fernando J.P. Listoni ${ }^{5}$ e Márcio G. Ribeiro ${ }^{4 *}$
}

\begin{abstract}
Bolaños C.A.D., Pantoja J.C.F., Alves A.C., Risseti R.M., Listoni F.J.P. \& Ribeiro M.G. 2014. [Milk quality indicators from cows bred on silvopastoral system in Cauca Valley, Colombia.] Qualidade do leite de vacas criadas no sistema silvipastoril no Vale do Cauca, Colômbia. Pesquisa Veterinária Brasileira 34(2):134-140. Departamento de Higiene Veterinária e Saúde Pública, Universidade Estadual Paulista Júlio de Mesquita Filho, Botucatu, SP 18618-970, Brazil. E-mail: mgribeiro@fmvz.unesp.br

The silvopastoral system is characterized by increasing the production of milk with a greater number of cows per hectare due to the higher amount of protein in the diet. In silvopastoral system cows are fed in addition to pasture, small trees and shrubs. The aim of this study was determinate the main indicators of milk quality and mastitis causal agents in cows bred on silvopastoral system. We evaluated the composition (fat, total protein, lactose, solids, dry extract, nonfat dry and urea nitrogen), somatic cell count (SCC), total bacterial count (TBC), occurrence of clinical and subclinical mastitis, microbiological isolation, in vitro antimicrobial sensitivity profile and detection of antimicrobial residues in milk produced by 100 cows raised in silvopastoral systems, as well as the bulk tank and churns in farms of Cauca Valley, Colombia. The concentration of the major constituents of milk were $3.24 \%$ fat, $3.27 \%$ total protein, $4.40 \%$ lactose, $10.62 \%$ dry extract, $8.57 \%$ nonfat dry and $15.82 \mathrm{mg} / \mathrm{dL}$ urea nitrogen, while the bulk tank and churns was $3.51 \%$ fat, $3.20 \%$ total protein, $4.34 \%$ lactose, $11.72 \%$ dry extract, $8.47 \%$ nonfat dry and $14.57 \mathrm{mg} / \mathrm{dL}$ urea nitrogen. The cell count of the cows and the bulk tank was $141,252.75 \mathrm{CS} / \mathrm{mL}$ and $363,078.05 \mathrm{CS} / \mathrm{mL}$ respectively. The TBC mean in cows and the bulk tank was 4,466.84 CFU/mL and 24,547.01 CFU/mL respectively. The main microorganisms isolated from the udder cows were Corynebacterium bovis, Staphylococcus aureus, Staphylococcus hyicus, Staphylococcus spp., Streptococcus dysgalatiae, while the bulk tank were identified more often Streptococcus spp., Enterobacter cloacae, Hafnia alveii, hemolytic Streptococcus and Streptococcus spp. Antimicrobial residues in cow milk and bulk or churn were detected in $30 \%$ and $86 \%$ respectively. The silvopastoral system showed to be good alternative to milk production in cow. However is important the care with antimicrobial residues in milk and the analysis of all quality parameters to ensure a differentiated product.
\end{abstract}

INDEX TERMS: Silvopastoral, cattle, mastitis, SCC, TBC, antimicrobial residues.

\footnotetext{
${ }^{1}$ Recebido em 11 de outubro de 2013.

Aceito para publicação em 7 de janeiro de 2014.

${ }^{2}$ Médica Veterinária Autônoma, Av. Panamericana, Carrera 13, Barrio Ciudad Jardín, Manzana D, casa 15, San Juan de Pasto, Colômbia.

${ }^{3}$ Pós-Graduandos do Departamento de Higiene Veterinária e Saúde Pública, Faculdade de Medicina Veterinária e Zootecnia (FMVZ), Universidade Estadual Paulista (Unesp), Campus de Botucatu, Cx. Postal 560, Botucatu, SP 18618-970, Brasil.

${ }^{4}$ Docentes do Departamento de Higiene Veterinária e Saúde Pública, FMVZ-Unesp, Cx. Postal 560, Botucatu, SP 18618-970. *Autor para correspondência: mgribeiro@fmvz.unesp.br

${ }^{5}$ Técnico em Laboratório do Departamento de Higiene Veterinária e Saúde Pública, FMVZ-Unesp, Cx. Postal 560, Botucatu, SP 18618-970.
}

RESUMO.- 0 sistema silvipastoril caracteriza-se por aumentar a produção de leite, com maior número de vacas por hectare devido ao maior aporte de proteína na dieta. Neste sistema as vacas são alimentadas, além do pasto, de pequenas árvores e arbustos. 0 objetivo do presente estudo foi determinar os principais indicadores de qualidade do leite e agentes causais de mastite em vacas criadas em sistema silvipastoril. Foram avaliadas a composição (teor de gordura, proteína total, lactose, extrato seco, extrato seco desengordurado e nitrogênio uréico), contagem de células somáticas (CCS), contagem bacteriana total (CBT), 
ocorrência de mastite clínica e subclínica, isolamento microbiológico, perfil de sensibilidade bacteriana "in vitro" e detecção de resíduos antimicrobianos no leite produzido por 100 vacas, bem como do tanque de expansão e latões em propriedades do Vale do Cauca, Colômbia. Os teores médios dos principais constituintes do leite foram 3,24\% de gordura, 3,27\% de proteína total, 4,40\% de lactose, $10,62 \%$ de extrato seco, $8,57 \%$ de extrato seco desengordurado e $15,82 \mathrm{mg} / \mathrm{dL}$ de nitrogênio uréico, enquanto do tanque de expansão e latões foi 3,51\% de gordura, 3,20\% de proteína total, $4,34 \%$ de lactose, $11,72 \%$ de extrato seco, $8,47 \%$ de extrato seco desengordurado e $14,57 \mathrm{mg} /$ $\mathrm{dL}$ de nitrogênio uréico. A celularidade média dos quartos mamários e do tanque de expansão foi 141.252,75 $\mathrm{CS} / \mathrm{mL}$ e 363.078,05 CS/mL respectivamente. A CBT média dos quartos mamários e do tanque de expansão foi $4.466,84 \mathrm{UFC} / \mathrm{mL}$ e $24.547,01 \mathrm{UFC} / \mathrm{mL}$. Os principais micro-organismos isolados dos quartos mamários foram Corynebacterium bovis, Staphylococcus aureus, Staphylococcus hyicus, Staphylococcus spp., Streptococcus dysgalatiae, enquanto do tanque de expansão foram identificados Streptococcus spp., Enterobacter cloacae, Hafnia alveii, Streptococcus hemolítico e Streptococcus spp., com maior frequência. A presença de resíduos de antimicrobianos em leite de vacas e do tanque ou latão foi detectada em $30 \%$ e $86 \%$ das amostras, respectivamente. 0 sistema silvipastoril mostrou ser uma boa alternativa para produção de leite em vacas. No entanto, são necessários cuidados no tratamento mamário para evitar resíduos no leite e a análise de todos os parâmetros de qualidade para garantir um produto diferenciado.

TERMOS DE INDEXAÇÃO: Silvipastoril, bovino, mastite, CCS, CBT, resíduos de antimicrobianos.

\section{INTRODUÇÃo}

Na última década, o sistema silvipastoril tem se destacado como método alternativo de produção de leite de vacas adotado em alguns países das Américas. Neste sistema de produção, os animais têm à disposição para a alimentação, além do pasto, pequenas árvores e arbustos espalhados nas pastagens, que se caracterizam por conter elevado teor protéico nas folhas (Murgueitio \& Ibrahim 2001, Calle, Montagnini \& Zuluaga 2007). Dentre estas árvores para produção silvipastoril, são utilizadas a Acácia (Acacia magnum), Aliso (Alnus spp.), Morera (Morus alba), Leucena (Leucaena leucocephala), Nacedero (Trichantera gigantea) e Gliricídia (Gliricidia sepium) (Mahecha 2002). 0 sistema silvipastoril tem sido utilizado principalmente em Cuba, Venezuela, México, Nicarágua e Colômbia. No Brasil, o uso do sistema silvipastoril é incipiente devido à criação principalmente extensiva dos animais (Fioravante 2012).

O sistema silvipastoril representa uma alternativa de produção sustentável, que reduz o impacto ambiental dos sistemas de produção tradicionais, aumentando o número de animais por unidades de área e incrementa a dieta dos animais pelo maior aporte de proteína. Ademais, diminui o uso de fertilizantes pela fixação biológica do nitrogênio (Urbano et al. 2006, Fioravante 2012).
A maioria dos estudos com o sistema silvipastoril nas Américas tem focado nos constituintes nutricionais destas árvores e outras forrageiras fornecidas às vacas (Hernández \& Ponce 2004). No entanto, número reduzido de estudos tem se preocupado como os indicadores de qualidade do leite e a ocorrência da mastite em vacas mantidas no sistema silvipastoril. Neste contexto, o presente estudo investigou os principais constituintes do leite, contagem bacteriana total, contagem de células somáticas, presença de resíduos de antimicrobianos e ocorrência de mastite no leite de vacas criadas nos sistema silvipastoril, no Vale do Cauca, Colômbia.

\section{MATERIAL E MÉTODOS}

Propriedades. 0 estudo foi realizado no primeiro semestre de 2013 em sete propriedades rurais do Vale do Cauca, localizado na região sudeste da Colômbia, caracterizado pela produção de leite no sistema silvipastoril. Estas propriedades possuem, em comum, a presença de árvores para pastagem direta, com espécies arbóreas como Leucena (Leucaena leucocephala), Algaroba (Prosopis juliflora), Botão de ouro (Tithonia diversifolia) e Gliricídia (Gliricidia sepium) consorciadas com pastagens gramíneas do tipo brachiaria (Brachiaria brizanta) e estrela africana (Cynodon plectostachyus). Das sete propriedades amostradas, três possuíam Leucena, duas Botão de ouro e duas Algaroba e Gliricídia. Todas as propriedades possuíam entre 50 a 500 animais em lactação, das quais duas em regime de ordenha manual e cinco com ordenha mecânica. Todas as propriedades entregavam leite à cooperativa Cogancevalle e se encontravam em zona livre de Febre Aftosa, com vacinação, conforme mapa da Organização Mundial da Saúde Animal (OIE 2013).

Animais e coleta de material. Foram coletadas amostras de 100 vacas das raças Lucerna, Jersey, Gir, Pardo Suíço, Holandesa e animais mestiços, provenientes de propriedades com sistema silvipastoril. Os animais estavam entre primeira e sétima lactações e produção média de 18 litros/dia. A coleta de leite $(15 \mathrm{~mL})$ foi efetuada uma única vez, antes da ordenha, nas 100 vacas. Foi realizada de forma asséptica, após higienização dos tetos com iodo (1\%), dispondo o material em tubos Falcon (estéreis), com tampa de rosca. Para avaliação da composição, contagem de células somáticas (CCS) e contagem bacteriana total (CBT), o material foi colhido em frascos apropriados contendo conservante celular de leite bronopol e azidiol, respectivamente. 0 mesmo processo foi realizado em amostras de leite compostas coletadas do tanque de expansão $(n=5)$ e latões $(n=2)$ das sete propriedades. 0 material foi refrigerado nas propriedades em caixas isotérmicas $\left(4-8^{\circ} \mathrm{C}\right)$ e congelado $\left(-20^{\circ} \mathrm{C}\right)$, no mesmo dia, visando o transporte para o Brasil, para a realização de diferentes técnicas diagnósticas. Para o transporte do leite, da Colômbia para o Brasil, foram obtidas todas as autorizações exigidas pelo Ministério da Agricultura, Pecuária e Abastecimento do Brasil (MAPA), e do Ministério da Agricultura e Desenvolmiento Rural da Colômbia (MADR). Após o processamento do leite nas diferentes técnicas diagnósticas, todas as amostras foram inativadas por autoclavação $\left(120^{\circ} \mathrm{C} / 30\right.$ minutos), previamente ao descarte.

Diagnóstico de mastite. 0 diagnóstico da mastite clínica foi realizado com base nas alterações macroscópicas do leite (presença de grumos, pus, sangue ou dessora) na prova da caneca telada de fundo escuro (Tamis), na presença de sinais clínicos de inflamação na glândula mamária (edema, hiperemia, nódulos, abscessos) e/ou sinais sistêmicos nos animais (Radostits et al. 2007). A mastite subclínica foi diagnosticada utilizando o teste clássico do "California Mastitis Test" (CMT) (Schalm et al. 1971). 
Isolamento e identificação dos micro-organismos. Todas as amostras de leite foram semeadas nos meios de ágar suplementado com sangue bovino (5\%) desfibrinado e ágar Mac Conkey, em condições de aerobiose a $37^{\circ} \mathrm{C}$, mantidas por 72 horas. Os micro-organismos foram identificados segundo as características morfo-tintoriais, bioquímicas e de cultivo (Quinn et al. 2011). Colônias bacterianas isoladas no meio de Mac Conkey foram submetidas às provas bioquímicas no meio da Escola Paulista de Medicina-EPM (glicose, gás, LTD, $\mathrm{H}_{2} \mathrm{~S}$ e urease), MILi (motilidade, indol e lisina) e Citrato, visando à identificação de enterobactérias (Trabulsi et al. 1999). Colônias no meio de ágar sangue sugestivas de estafilococos foram submetidas à coloração de Gram, prova da catalase e repicadas no Manitol Salt ágar e ágar DNASE. Estas colônias foram submetidas também à prova de coagulase em tubo, visando diferenciar os estafilococos coagulase positiva (ECP) dos estafilococos coagulase negativa (ECN). Colônias no ágar sangue sugestivas de estreptococos, foram submetidas à coloração de Gram, prova de catalase e prova de CAMP visando diferenciar Streptococcus agalactiae de Streptococcus dysgalactiae (Quinn et al. 2011).

Perfil de sensibilidade microbiana in vitro. Os micro-organismos isolados foram submetidos à prova de sensibilidade microbiana in vitro pelo método de difusão com discos (CLSI/NCCLS 2006), no laboratório de diagnóstico microbiológico da FMVZ-UNESP/Botucatu, SP, utilizando os principais antimicrobianos empregados na Colômbia para tratamento da mastite, a saber: amoxicilina/ácido clavulânico $(30 \mathrm{mcg})$, ampicilina $(10 \mathrm{mcg})$, cefalexina (30mcg), cefalônio anidro $(30 \mathrm{mcg})$, espiramicina (100 $\mathrm{mcg})$, lincomicina $(2 \mathrm{mcg})$, neomicina $(30 \mathrm{mcg})$, penicilina (10 UI) e sulfadiazina/trimetoprim (25mcg).

Contagem eletrônica de células somáticas. Todas as amostras de leite dos animais, dos tanques de expansão e latões foram colhidas em tubos apropriados de plástico, homogeneizadas com conservante celular de leite Bronopol $^{\circledR}$ (2-bromo-2-nitropropano-1,3-diol) e dispostas em caixas apropriadas, congeladas a $-20^{\circ} \mathrm{C}$ (Barkema et al. 1997), visando à contagem eletrônica de células somáticas por citometria de fluxo, de acordo com as recomendações técnicas do equipamento (Somacount $\left.300^{\circledR}\right)^{6}$. As análises de CCS foram realizadas na Clínica do Leite, ESALQ-USP/ Piracicaba, SP. Na Colômbia não existe parâmetro de celularidade específico exigido pelos órgãos competentes do país. Assim, foi considerado normal o leite com $\leq 200.000 \mathrm{CS} / \mathrm{mL}$ (NMC 1987) e comparados os resultados do presente estudo com a Instrução Normativa 62 (IN-62) do Brasil (Brasil 2011).

Contagem bacteriana total. Para avaliação da contagem bacteriana total, o material colhido foi adicionado em frasco apropriado contendo o Azidiol ${ }^{\circledR}$ (azida sódica e cloranfenicol) e imediatamente congelado até o processamento na Clínica do Leite, ESALQ-USP/Piracicaba, SP, pelo método de citometria de fluxo (PO ANA 010).

Avaliação de resíduos de antimicrobianos. A detecção de resíduos foi realizada no leite procedente de todos os animas, e dos tanques de expansão e latões, utilizando o kit comercial, conforme as recomendações do fabricante (Delvotest SP-NT $\left.{ }^{\circledR}\right)^{7}$, indicado para o diagnóstico dos principais grupamentos de antimicrobianos disponíveis em medicina veterinária. As amostras foram colhidas e acondicionadas em frascos esterilizados e congeladas $\left(-20^{\circ} \mathrm{C}\right)$ até o processamento. A detecção de resíduos por este método utiliza ampolas de meio de cultura contendo Bacillus stearothermophilus var. calidolactis. São adicionados $0,1 \mathrm{~mL}$ de amostra de leite no receptáculo do kit contento o micro-organismo e indicador de $\mathrm{pH}$, e mantidos em temperatura de $64^{\circ} \mathrm{C} \pm 0,5$ durante

\footnotetext{
${ }^{6}$ Somacount $300 ®$, Bentley, USA.

${ }^{7}$ Devotest SP-NT®: DMS Food Specialities Ingredients, The Netherlands.
}

3 horas, em banho-maria. Na ausência de antimicrobianos ocorre a multiplicação bacteriana, produção de ácido e alteração da cor original do indicador (de púrpura para amarelo). Na presença de resíduos de antimicrobianos a multiplicação bacteriana é retardada ou inibida, ocorrendo inibição ou acidificação pobre do meio (tonalidade púrpura a azulada).

Análise da composição do leite. A análise dos constituintes do leite (gordura, proteína total, lactose, extrato seco, extrato seco desengordurado e nitrogênio uréico) foi realizada na Clínica do Leite, ESALQ-USP/Piracicaba, SP, pelo método de infravermelho (PO ANA 009).

A CCS, CBT, análises de composição e resíduos de antimicrobianos foram realizadas, em média, um mês após a colheita do leite.

Análise estatística e tamanho amostral. 0 número de rebanhos incluídos no estudo foi calculado com base na média e desvio padrão da CCS do leite de tanques de expansão descrita em estudos prévios realizados na Colômbia (Calderón \& Rodríguez 2008, Trujillo et al. 2010, Calderón et al. 2011,). Os cálculos foram baseados em CCS média de $500.000,00 \mathrm{CS} / \mathrm{mL}$ e desvio padrão de 300.000,00 CS/mL, com margem de erro de 150.000,00 CS/ $\mathrm{mL}$ e nível de confiança $(\alpha)$ de $5 \%$. A estimativa da prevalência de mastite subclínica (unidade de análise $=$ vaca) na população alvo (30 rebanhos da região com média de 50 animais em lactação = 1.500 animais) foi baseada em dados reportados anteriormente de propriedades Colombianas (Trujillo et al. 2010). Para estimar uma prevalência de $50 \%$, com margem aceitável de erro de $10 \%$ (e nível de confiança de 5\%), uma amostra mínima de 90 vacas foi necessária. Os cálculos do tamanho da amostra foram realizados de acordo com os métodos descritos por Dohoo et al. (2010), determinado pela fórmula:

$$
\begin{aligned}
& N=\frac{N P(1-P)}{\frac{d^{2}}{Z_{1-\alpha / 2}^{2}} \times(N-1)+P \times(1-P)} \\
& \mathrm{N}=\text { tamanho da população (finita), } \\
& P=\text { prevalência estimada na população, } \\
& d=\text { margem de erro aceitável. }
\end{aligned}
$$

Os resultados obtidos foram analisados por estatística descritiva geral no programa estatístico InfoStat ${ }^{\circledR}$, considerando intervalos de confiança de $95 \%$ e nível de significância para valores de $\mathrm{P}<0,05$. Os dados de CCS, CBT e gordura foram transformados em logarítmo natural devido a desvios de um padrão Gaussiano de distribuição. Os resultados da composição do leite, CCS e CBT foram submetidos à análise de variância e o teste de Tuckey foi usado para ajustar o valor-P resultante de comparações múltiplas entre grupos. Devido à assimetria acentuada da distribuição da lactose, o teste de Kruskal Wallis foi utilizado para comparação entre os grupos (Pagano \& Gauvreau 2003, Daniel 2009).

\section{RESULTADOS E DISCUSSÃO}

\section{Composição do leite}

Os resultados referentes aos teores de gordura, proteína total, lactose, extrato seco (ES), extrato seco desengordurado (ESD) e nitrogênio uréico (NU) para amostras individuais e coletivas (tanque de expansão e latão) são apresentados nos Quadros 1 (análise geral dos constituintes) e Quadro 2 (segundo diferentes árvores).

Em geral, os teores da composição do leite foram encontrados dentro dos valores considerados normais para vacas (Singh \& Bennett 2002). O teor de gordura, extrato seco e lactose foram menores do que os relatados em estudo similar em Havana, Cuba (Hernández \& Ponce 2004) 
Quadro 1. Principais constituintes do leite individual (ind) e coletivo (col) (tanques de expansão e latões) de vacas criadas no sistema silvipastoril no Vale do Cauca. Colômbia, 2013

\begin{tabular}{|c|c|c|c|c|c|c|c|c|c|c|c|}
\hline \multirow[t]{2}{*}{ Variável } & \multicolumn{2}{|c|}{ Média/DP } & Mediana & \multicolumn{2}{|c|}{ Mínimo } & \multicolumn{2}{|c|}{ Máximo } & \multicolumn{2}{|c|}{ LI (95\%) } & \multicolumn{2}{|c|}{ LS (95\%) } \\
\hline & Ind & Col & Ind Col & Ind & Col & Ind & Col & Ind & Col & Ind & Col \\
\hline (1) & & & $3,263,53$ & 2,57 & 3,4 & 3,8 & 3,6 & 3,17 & 3,43 & 3,34 & 3,64 \\
\hline total (\%) & $3,27 \pm$ & 3,2 & $3,24 \quad 3,15$ & 2,37 & 3,1 & 4,83 & 3,48 & 3,1 & 2,96 & 3,38 & 3,34 \\
\hline Lactose (\% & $4,4 \pm$ & $4,34 \pm$ & $4,47 \quad 4,34$ & 2,84 & 4,21 & 4,92 & 4,47 & 3,64 & 4,21 & 3,66 & 4,47 \\
\hline ES (\%) & $10,62 \pm 1,39$ & $11,72 \pm 0,54$ & $10,4 \quad 11,8$ & 8,09 & 10,84 & 15 & 12,44 & 9,97 & 11,01 & 10,84 & 12,59 \\
\hline ESD (\%) & $8,57 \pm 0,51$ & $8,47 \pm 0,16$ & $8,58 \quad 8,48$ & 7,34 & 8,26 & 10,02 & 8,72 & 8,42 & 8,25 & 8,74 & 8,71 \\
\hline $\mathrm{NU}(\mathrm{mg} / \mathrm{dl})$ & $15,82 \pm 3,24$ & $14,57 \pm 3,10$ & $15,6 \quad 14,9$ & 8,2 & 10,3 & 23,5 & 18,2 & 14,58 & 10,4 & 16,62 & 19,4 \\
\hline
\end{tabular}

*Variável transformada em $\log 10 . \mathrm{Col}=$ Coletivo; LI = Limite Inferior; ES = Extrato Seco; LS = Limite Superior; ESD

= Extrato; Seco Desengordurado; Ind = Individual; NU = Nitrogênio Ureico.

Quadro 2. Análise de variância da composição do leite individual (ind) e coletivo (col) (tanques de expansão e latões) segundo diferentes árvores utilizadas no sistema silvipastoril no Vale do Cauca. Colômbia, 2013

\begin{tabular}{|c|c|c|c|c|c|c|c|c|c|c|}
\hline \multirow[t]{2}{*}{ Árvore } & Gordura & Proteína total & \multicolumn{2}{|c|}{ Lactose } & \multicolumn{2}{|c|}{ ES } & \multicolumn{2}{|c|}{ ESD } & \multicolumn{2}{|c|}{$\mathrm{NU}$} \\
\hline & Ind. Col. & Ind. Col. & Ind. & Col. & Ind. & Col. & Ind. & Col. & Ind. & Col. \\
\hline $\begin{array}{l}\text { Leucena } \\
\text { (Leucaena leucocephala) }\end{array}$ & $3,19^{\mathrm{a}} 3,55^{\mathrm{a}}$ & $3,10^{\mathrm{a}} 3,12^{\mathrm{a}}$ & $3,65^{\mathrm{a}}$ & $4,36^{a}$ & $10,16^{\mathrm{a}}$ & $11,95^{\mathrm{a}}$ & $8,44^{\mathrm{a}}$ & $8,42^{\mathrm{a}}$ & $14,93^{\mathrm{a}}$ & $13,9^{a}$ \\
\hline $\begin{array}{l}\text { Botão de ouro } \\
\text { (Tithonia diversifolia) }\end{array}$ & $3,4^{\mathrm{b}} 3,55^{\mathrm{a}}$ & $3,21^{\mathrm{a}} 3,16^{\mathrm{a}}$ & $3,63^{\mathrm{a}}$ & $4,34^{\mathrm{a}}$ & $11,19^{b}$ & $11,95^{a}$ & $8,44^{\mathrm{a}}$ & $8,43^{\mathrm{a}}$ & $16,88^{b}$ & $17,3^{\mathrm{a}}$ \\
\hline $\begin{array}{l}\text { Algaroba } \\
\text { (Prosopis juliflora) e/ou } \\
\text { Gliricídia } \\
\text { (Gliricidia sepium) }\end{array}$ & $3,08^{\mathrm{a}} 3,41^{\mathrm{a}}$ & $3,52^{\mathrm{b}} 3,23^{\mathrm{a}}$ & $3,65^{\mathrm{a}}$ & $4,34^{\mathrm{a}}$ & $10,35^{\mathrm{a}}$ & $11,29^{a}$ & $8,86^{\mathrm{b}}$ & $8,62^{\mathrm{a}}$ & $15,36^{\mathrm{ab}}$ & $11,5^{\mathrm{a}}$ \\
\hline
\end{tabular}

e na região de Yucatán, México (Aguilar-Pérez et at. 2001, Tinoco-Magaña et al. 2012) em vacas alimentadas com leucena (Leucaena leucophala). No entanto, o teor de proteína nas vacas amostradas do presente estudo foram maiores do que o observado nos estudos supracitados. A alta proteína no leite das vacas do presente estudo provavelmente encontra reflexo no elevado teor protéico das folhas destas árvores consumidas pelos animais em sistema silvipastoril (Philips \& Sorensen 1993). 0 extrato seco desengordurado nos animais amostrados também foi maior do que o obtido em vacas mantidas em sistema silvipastoril na província de Matanzas, em Cuba (González et al. 2002). 0 alto teor de ESD nas vacas do presente estudo poderia ser creditado pelo conteúdo de nutrientes das folhas das árvores utilizadas no sistema silvipastoril (Aguilar-Pérez 2001).

Quando comparados os mesmos constituintes em sistemas leiteiros convencionais no estado de Minas Gerais, Brasil (Cofani dos Santos et al. 2009), se observou que as vacas no sistema silvipastoril amostradas no presente estudo apresentaram maiores valores de nitrogênio uréico. Tal resultado provavelmente encontra reflexo na elevada capacidade da Leucena, Botão de ouro, Algaroba e Gliricídia de fixar o nitrogênio no solo, elevando os teores de nitrogênio uréico no leite, à semelhança da proteína (Calle et al. 2007).

Os teores de gordura, proteína total, extrato seco, extrato seco desengordurado e nitrogênio uréico do leite individual das vacas revelaram diferenças estatisticamente significantes $(\mathrm{p}<0,05)$ segundo o tipo de árvore utilizado no sistema silvipastoril, visto que o botão de ouro (Tithonia diversifolia) mostrou maior influência sobre os teores destes constituintes. Mahecha et al. (2007) e Mahecha \& Rosales
(2005), na Colômbia, também observaram elevados teores de gordura, ES e NU em vacas no sistema silvipastoril. Estes autores atribuíram tal achado ao elevado conteúdo de carboidratos estruturais das folhas do botão de ouro, que participam na formação da gordura do leite e do conteúdo de nitrogênio total.

No presente estudo, nenhum dos teores de composição revelou diferenças significativas $(p>0,05)$ nas amostras de leite coletivo (Quadros 1 e 2). A leucena (Leucaena leucocephala) não exerceu influência sobre os componentes do leite nos animais amostrados em produção silvipastoril. Resultado similar foi obtido por Kakengi et al. (2001) utilizando leucena na Tanzânia, onde somente no extrato seco foram observadas diferenças significativas.

\section{Contagem de células somáticas}

Os valores de CCS nas amostras individuais (Quadro 3) indicaram bom status da saúde do úbere dos animais amostrados, acusando celularidade inferior a $200.000 \mathrm{CS} / \mathrm{mL}$. Esta celularidade do leite é considerada normal para vacas e também é considerado o ponto de corte para determinar mastite subclínica (Dohoo \& Leslie 1991). A média geométrica da CCS das vacas amostradas em produção silvipastoril foi menor do que a celularidade relatada em estudos de sistema orgânico na Suíça (Roesch et al. 2007) e no Brasil (Ribeiro et al. 2009), em sistema convencional no Brasil (Cofani dos Santos et al. 2009) e no sistema silvipastoril na Argentina (Casemiro et al. 2008). Em contraste, a CCS do leite coletivo (tanque de expansão e latões) acusou valores altos, indicando a presença nas propriedades amostradas de animais com CCS elevada que acaba incrementando os 
níveis de CCS do tanque de expansão ou leite coletivo (Smith 1996). Estudos realizados na Holanda confirmaram a possibilidade de congelamento do leite por até três meses, com reduzida ou nenhuma influência na celularidade tampouco CBT (Barkema et al. 1997).

\section{Contagem bacteriana total}

A média geométrica (Quadro 3) do leite coletivo (tanques de expansão e latões) acusou valor menor do que o limite exigido no Brasil de 600.000 UFC/mL (BRASIL, 2011) e de 700.000 UFC/mL exigido na Colômbia (MADR, 2011). Estudos realizados no Brasil (Cofani dos Santos et al. 2009) e na Namíbia (Bille et al. 2009) relataram valores de CBT menores em sistemas convencionais, embora Langoni et al. (2011) no Brasil, relataram níveis altos de CBT em sistemas orgânicos de produção. Baixa CBT indica boas práticas de ordenha e é um dos principais parâmetros avaliados na mensuração da qualidade do leite (Santos \& Fonseca 2007).

\section{Ocorrência e etiologia de mastite}

Não foram observados animais com mastite clínica no referente estudo. Em contraste, $43 \%$ (IC $=32,9 \%$ - 52,8\%) dos animais reagiram no CMT indicando alta ocorrência de mastite subclínica. A ausência de casos clínicos de mastite e a alta prevalência de mastite subclínica sugerem o predomínio de infecções por micro-organismos contagiosos (Santos \& Fonseca 2007) nas vacas amostradas (Quadro 4). Em contraste, no leite coletivo (tanques de expansão e latões) foi observada maior prevalência de agentes ambientais, como enterobactérias e estreptococos (Quadro 4). Este último achado indica problemas de armazenamento do leite ou contaminação dos utensílios e equipamentos de ordenha, que reflete no aumento de micro-organismos ambientais no leite coletivo (Santos \& Fonseca 2007).

Embora 64\% das amostras individuais não acusaram isolamento microbiano, os micro-organismos isolados como Staphylococcus spp., Corynebacterium bovis, Staphylococcus aureus, Streptococcus spp., Streptococcus dysgalactiae e Staphylococcus hyicus (Quadro 4) são indicativos de mastite contagiosa nos animais amostrados (Nickerson \& Philpot 2000). Estudos realizados no Brasil em leite produzido em sistema orgânico (Ribeiro et al. 2009, Langoni et al. 2009, 2011), assim como em sistemas de produção

Quadro 3. Valores de CCS e CBT para amostras individuais (ind) e coletivas (col) (tanques de expansão e latões) de leite de vacas produzido em sistema silvipastoril no Vale do Cauca, Colômbia, 2013

\begin{tabular}{|c|c|c|c|c|}
\hline \multirow[t]{2}{*}{ Medida } & \multicolumn{2}{|c|}{$\mathrm{CCS}(\mathrm{CS} / \mathrm{mL})^{*}$} & \multicolumn{2}{|c|}{ CBT (UFC/mL)* } \\
\hline & Ind. & Col. & Ind. & Col. \\
\hline Média & $5,15 \pm 0,69$ & $5,56 \pm 0,34$ & $3,65 \pm 0,34$ & $4,36 \pm 0,89$ \\
\hline Mediana & 5,14 & 5,66 & 3,6 & 4,04 \\
\hline Média geométrica & $141.252,75$ & $363.078,05$ & $4.466,84$ & $24.547,01$ \\
\hline Mínimo & 3,48 & 4,87 & 3,3 & 3,3 \\
\hline Máximo & 6,77 & 5,77 & 4,82 & 5,58 \\
\hline LI $(95 \%)$ & $123.367,17$ & $201.929,61$ & $20.720,49$ & 5291,76 \\
\hline LS (95\%) & 161.733 .51 & 652.829 & 962,94 & $113.867,56$ \\
\hline
\end{tabular}

*Dados originais transformados em Log10. Ind = Individual; LI = Limite Inferior; Col = Coletivo; LS = Limite Superior.
Quadro 4. Micro-organismos isolados em amostras de leite individual e coletivo produzido nos sistemas silvipastoris no Vale do Cauca. Colômbia, 2013

\begin{tabular}{lccc}
\hline Micro-organismo & Individual & & Coletivo \\
\cline { 2 - 2 }$(\mathrm{n}=100)$ & & $(\mathrm{n}=7)$ \\
\hline Staphylococcus spp. & 17 & - \\
Corynebacterium bovis & 5 & - \\
Staphylococcus aureus & 4 & - \\
Streptococcus spp. & 3 & 29 \\
Micrococcus spp. & 3 & \\
Streptococcus dysgalactiae & 2 & \\
Staphylococcus hyicus & 1 & \\
Klebsiella oxytoca & 1 & \\
Hafnia alvei & - & - \\
Streptococcus $\alpha$-hemolítico & - & \\
Enterobacter cloacae & - & \\
Negativo & 64 & \\
TOTAL & 100 & & 14 \\
& & & 14 \\
& & & 100
\end{tabular}

convencional (Cardoso et al. 2000, Barbosa 2002) e na Colômbia (Calderón \& Rodríguez 2008, Calderón et al. 2011), confirmaram a maior frequência dos casos de mastite subclínica por bactérias contagiosas (Santos \& Fonseca 2007). O predomínio de micro-organismos contagiosos nos casos de mastite subclínica pode ser justificado pela presença destas bactérias na microbiota da pele, mucosas, úbere e tetos dos animais, favorecendo infecções via ascendente canal do teto. Ao invadirem o epitélio mamário, os micro-organismos contagiosos desenvolvem estado inflamatório principalmente de forma subclínica, posto que possuem como hábitat a pele e mucosas, ao contrário dos ambientais, que em contato com o epitélio mamário comumente exteriorizam mastite clínica (Ribeiro 2008).

\section{Perfil de sensibilidade microbiana in vitro}

Os isolados mostraram maior sensibilidade in vitro frente à cefalexina (100\%), cefalônio anidro (100\%) e amoxicilina/ácido clavulânico (90\%), seguido pela sulfadiazina/trimetoprim (85\%) e neomicina (80\%) (Quadro 5). Em contraste, a maior resistência das linhagens foi observada para espiramicina $(45 \%)$, lincomicina $(40 \%)$, ampicilina (30\%) e penicilina (15\%). A elevada efetividade in vitro das cefalosporinas pode ser creditada a indicação destes

Quadro 5. Perfil de sensibilidade microbiana in vitro de micro-organismos isolados do leite de vacas, provenientes de sistema silvipastoril do Vale do Cauca, Colômbia, 2013

\begin{tabular}{|c|c|c|c|c|c|c|c|}
\hline \multirow{3}{*}{ Antimicrobiano } & \multicolumn{2}{|c|}{ Sensível } & \multirow{2}{*}{\multicolumn{2}{|c|}{$\begin{array}{l}\text { Parcialmente } \\
\text { sensível }\end{array}$}} & \multicolumn{2}{|c|}{ Resistente } & \multirow[t]{3}{*}{ Total } \\
\hline & \multirow[t]{2}{*}{$\mathrm{N}$} & \multirow[t]{2}{*}{$\%$} & & & \multirow[t]{2}{*}{$\mathrm{N}$} & \multirow[t]{2}{*}{$\%$} & \\
\hline & & & $\mathrm{N}$ & $\%$ & & & \\
\hline Amoxicilina/ Ácido & 18 & 90 & 0 & 0 & 2 & 10 & 20 \\
\hline \multicolumn{8}{|l|}{ Clavulânico (30 mcg) } \\
\hline Ampicilina (10mcg) & 8 & 40 & 6 & 30 & 6 & 30 & 20 \\
\hline Cefalexina (30 mcg) & 20 & 100 & 0 & 0 & 0 & 0 & 20 \\
\hline Cefalônio anidro (30mcg) & 20 & 100 & 0 & 0 & 0 & 0 & 20 \\
\hline Espiramicina (100 mcg) & 2 & 10 & 9 & 45 & 9 & 45 & 20 \\
\hline Lincomicina (2 mcg) & 0 & 0 & 12 & 60 & 8 & 40 & 20 \\
\hline Neomicina (30 mcg) & 16 & 80 & 4 & 20 & 0 & 0 & 20 \\
\hline Penicilina (10 UI) & 10 & 50 & 7 & 35 & 3 & 15 & 20 \\
\hline Sulfadiazina/ & 17 & 85 & 3 & 15 & 0 & 0 & 20 \\
\hline
\end{tabular}

Trimetoprim (25 mcg)

$\overline{\mathrm{N}}=$ número, $\%=$ porcentagem . 
fármacos para o tratamento de micro-organismos contagiosos de mastite como estreptococos e estafilococos, que predominaram no presente estudo. Em contraste, a elevada resistência in vitro dos isolados frente à lincomicina e espiramicina poderia encontrar justificativa no uso, há décadas, destes fármacos no tratamento intramamário de vacas com mastite na Colômbia (Calderón et al. 2011). 0 uso prolongado destes fármacos poderia aumentar a pressão seletiva para linhagens multirresistentes (Ribeiro 2008). Neste contexto, a baixa eficácia in vitro da ampicilina e penicilina poderia ser justificada pela produção de beta-lactamases pelos isolados de estafilococos - prevalentes nos animais amostrados -, resultando em linhagens resistentes a estes fármacos do grupo das penicilinas e derivados (Trabulsi et al. 1999, Santos \& Fonseca 2007).

A presença de resistência dos isolados frente à lincomicina, espiramicina, ampicilina e penicilina, que se constituem em fármacos amplamente utilizados no tratamento da mastite bovina, reforçam a importância dos testes de sensibilidade in vitro previamente à instituição do tratamento de vacas com mastite, visando maximizar as taxas de cura e investigar a ocorrência de linhagens multirresistentes (Ribeiro 2008).

\section{Detecção de resíduos de antimicrobianos}

No presente estudo foi observado que $30 \%$ (IC = 28,86$39,14 \%$ ) das amostras individuais de leite foram positivas para a presença de resíduos de antimicrobianos. Estudos similares no Brasil (Ribeiro et al. 2009) detectaram resíduos em $2,7 \%$ das amostras coletadas de vacas criadas em sistema orgânico. No leite coletivo amostrado, a presença de resíduos de antimicrobianos foi detectada em 86\% dos tanques de expansão e latões. Estudos conduzidos em Trinidad \& Tobago (Adesiyun et al. 2005) em amostras de leite de vacas em produção coletivo convencional, detectaram a presença de antimicrobianos em 4,2\% da amostragem. A alta ocorrência de resíduos de antimicrobianos no leite de vacas na região amostrada na Colômbia é um achado preocupante, visto que os resíduos de fármacos podem causar reações orgânicas indesejáveis nos humanos, assim como determinam prejuízos na indústria para a produção de derivados lácteos (Santos \& Fonseca 2007). A alta ocorrência de resíduos de antimicrobianos no leite é reflexo direto do uso indevido ou não racional de antimicrobianos no tratamento da mastite (Ribeiro 2008). A presença de resíduos ocorre geralmente pela inobservância da carência dos antimastíticos em animais tratados por via intramamária ou via parenteral, pelo uso de antimicrobianos de vaca seca em animais na lactação, por antecipação do período seco das vacas, ou introdução de animais em tratamento no plantel (Nickerson \& Philpot 2000).

\section{CONCLUSÕES}

Os resultados do presente estudo revelaram baixa celularidade e CBT e teores normais dos componentes do leite - exceto a proteína total e nitrogênio uréico que se mostraram elevados, indicando boa qualidade do produto em vacas criadas no sistema silvipastoril, apesar da alta ocorrência de mastite subclínica.
A maior ocorrência de agentes ambientais no leite coletivo indica a necessidade de cuidados com a higiene do ambiente de ordenha, dos utensílios utilizados na prática da ordenha e acondicionamento do leite, enquanto a alta prevalência de micro-organismos contagiosos sinaliza a necessidade de intensificar as ações de boas práticas de ordenha e a adoção de pós-dipping e terapia de vaca seca, procedimentos indicados para o controle de micro-organismos contagiosos.

A ocorrência de resistência dos isolados aos antimicrobianos de uso no tratamento da mastite na região amostrada na Colômbia e a elevada presença de resíduos de antimicrobianos no leite são resultados preocupantes, reflexo do uso não racional de antimicrobianos nos animais, e devem ser motivo de esforços dos produtores silvipastoris da região, com intuito de evitar qualquer resíduo nocivo aos humanos, assegurando alta qualidade do leite produzido neste sistema alternativo de produção.

Agradecimentos.- Aos pecuaristas da cooperativa Cogancevalle por permitir a colheita das amostras. Aos médicos veterinários Andrés Sinisterra, Dario Alejandro Cedeño Quevedo, Esteban Cadena Vinueza e ao técnico pecuário Carlos Berrio Cavalli pela colaboração no contato com os pecuaristas, auxílio no transporte e processo de coleta do material. À Dra. Sonia Abe do MAPA, Brasil, pelo auxílio nos trâmites de importação do material. À Coordenação de Aperfeiçoamento de Pessoal de Nível Superior (CAPES), pela concessão de bolsa de mestrado (Proc. 146357-2).

\section{REFERÊNCIAS}

Adesiyun A.A., Stoute S. \& David B. 2005. Pre-processed bovine milk quality in Trinidad: prevalence and characteristics of bacterial pathogens and occurrence of antimicrobial residues in milk from collection centers. Food Control 18:312-320.

Aguilar-Pérez C.F., Cárdenas-Medina J.V. \& Santos-Flóres J.S. 2001. Efecto de la suplementación con Leucaena leucocephala sobre la productividad de vacas cruzadas, bajo dos cargas de pastoreo. Livest. Res. Rural Dev. 4(13). Disponível em <http://www.lrrd.org/lrrd13/4/agui134.htm> Acesso em 31 jul. 2013.

Barbosa C.P., Benedetti E., Ribeiro S.C.A. \& Guimarães E.C. 2002. Relação entre contagem de células somáticas (CCS) e os resultados do "California Mastitis Test" (CMT), no diagnóstico de mastite bovina. Biosci. J. 18:93-102.

Barkema H.W., Van der Schans J., Schukken Y.H., De Gee A.L.W., Lam T.J.G.M. \& Benedictus G. 1997. Effect of freezing on somatic cell count of quarter milk samples as determined by a fossomatic electronic cell counter. J. Dairy Sci. 80(2):422-426.

Bille P.G., Haradoeb B.R. \& Shigweda N. 2009. Evaluation of chemical and bacteriological quality of raw milk from Neudamm dairy farm in Namibia. Afr. J. Food Agric. Nutr. Dev. 9:1-13.

Brasil 2011. Ministério da Agricultura, Pecuária e Abastecimento. Instrução Normativa 62. Regulamento técnico de produção, identidade e qualidade do leite tipo A, o regulamento técnico de identidade e qualidade de leite cru refrigerado, o regulamento técnico de identidade e qualidade de leite pasteurizado e o regulamento técnico da coleta de leite cru refrigerado e seu transporte a granel. Diário Oficial da União, Brasília, DF, 29 dez., Seção 1, p.6.

Calderón A. \& Rodríguez V.C. 2008. Prevalencia de mastitis bovina y su etiología infecciosas en sistemas especializados en producción de leche en el altiplanos cundiboyasence (Colombia). Revta Colomb. Cienc. Pec. 21:582-589.

Calderón A.R., Rodríguez V.C.R., Arrieta G.B. \& Máttar S.V. 2011. Prevalence of mastitis in dual purpose cattle farms in Monteria (Colombia): etiology and antibacterial susceptibility. Revta Colomb. Cienc. Pec. 24:19-28.

Calle A., Montagnini F. \& Zuluaga A.F. 2007. Farmer's perceptions of sil- 
vopastoral system promotion in Quindio, Colombia. Bois For. Trop. 29(300):79-94.

Cardoso H.F.T., Carmo L.S. \& Silva N. 2000. Detecção da toxina 1 da síndrome do choque tóxico em amostras de $S$. aureus isoladas de mastite bovina. Arq. Bras. Med. Vet. Zootec. 52:7-10.

Casemiro J.R., Spanh E., De Petre A., Valenti R., Butus M., Diaz E., Duarte O., Chajud A., Rosales E. \& Montiel J. 2008. Producción lechera en un sistema silvipastoril mejorado. Ciencia, Docencia y Tecnología 36:215-255.

CLSI 2006. Performance Standards for Antimicrobial Ausceptibility Testing. Clinical and Laboratory Standards Institute (NCCLS). Fifteenth Informational Supplement. CLSI/NCCLS document M100-S15.

Cofani dos Santos L.G., De Nadai Fernandes E.A., Arruda M.B., Sarriés G.A., Blumer L. \& Barbosa F.J. 2009. Chemical composition of bovine Milk from Minas Gerais State, Brazil. J. Radioanal. Nucl. Chem. 282:493-496.

Colômbia 2011. Ministerio de Agricultura y Desarrollo Rural (MADR). Decreto número 1880 de 27 de mayo de 2011. Por el cual se señalan los requisitos para la comercialización de leche cruda para consumo humano directo en el territorio nacional. Disponível em <https://www. minagricultura.gov.co/Normatividad/ Paginas/ Decretos.aspx> Acesso em 31 jul. 2013.

Daniel W.W. 2009. Bioestatistics: a foundation for analysis in the health sciences. $9^{\text {th }}$ ed. Wiley, Philadelphia. 956p.

Delvotest ${ }^{\circledR}$ SP 5 PACK-NT. Standard diffusion test for the detection of antibacterial substances in milk. DSM Food Specialities B.V. The Netherlands. Disponível em <www.dsm-foodspecialities.com> Acesso em 31 jul. 2013.

Dohoo I.R. \& Leslie K.E. 1991. Evaluation of changes in somatic cell counts as indicators of new intramamary infections. Prev. Vet. Med. 10:225237.

Dohoo I., Martin W. \& Stryhn H. 2010. Veterinary Epidemiologic Research. 2nd ed. REV Inc., Charlottetown. 727p.

Fioravante C. 2012. A carne da floresta. Pesq. Fapesp 192:72-75.

González I., Vega J. \& Castillo R. 2002. Estudio de la calidad físico-química de la leche entera de vaca en un sistema silvipastoril. Trop. Subtrop. Agroecosyst. 1: 25-27. Disponível em <http://www.redalyc.org/ pdf/939/93911238004.pdf> Acesso em 31 jul. 2013.

Hernández R.R. \& Ponce P.C. 2004. Efecto del silvopastoreo como sistema sostenible de explotación bovina sobre la composición de la leche. Livestock Res. Rural Dev. 16(6). Disponível em <http://www.lrrd.org/ Irrd16/6/hern16043.htm> Acesso em 31 jul. 2013.

Kakengi A.M., Shem M.N., Mtengeti E.P. \& Ostyina R. 2001. Leucaena leucocephala leaf meal as supplement to diet of grazing dairy cattle in semiarid Western Tanzania. Agrofor. Syst. 52:73-82.

Langoni H., Sakiyama D.T.P., Guimarães F.F., Menozzi B.D. \& Costa da Silva R. 2009. Aspectos citológicos e microbiológicos do leite em propriedades no sistema orgânico de produção. Pesq. Vet. Bras. 29:881-886.

Langoni H., Sakiyama D.T.P., Guimarães F.F., Camossi L.G. \& Vieira da Silva A. 2011. Contagem de células somáticas e de microrganismos mesófilos aeróbios em leite cru orgânico produzido em Botucatu (SP). Vet. Zootec. 18:653-660.

Mahecha L. 2002. El silvopastoreo: una alternativa de producción que disminuye el impacto ambiental de la ganadería bovina. Revta. Colomb. Cienc. Pec. 15:226-231.

Mahecha L. \& Rosales M. 2005. Valor nutricional del follaje de botón de oro Tithonia diversifolia (Hemsl) Gray, en la producción animal en el trópico. Livest. Res. Rural Dev. 17(9). Disponível em <http://www.lrrd.org/ lrrd17/9/mahe17100.htm> Acesso em 31 jul. 2013.
Mahecha L., Escobar J.P., Suárez J.F. \& Restrepo L.F. 2007. Tithonia diversifolia (hemsl) Gray (Botón de oro) como suplemento forrajero de vacas. Livest. Res. Rural Dev. 19(2). Disponível em < http://www.lrrd.org/ lrrd19/2/mahe19016.htm > Acesso em 31 jul. 2013.

Murgueitio E. \& Ibrahim M. 2001. Agroforestería pecuaria para la reconversión de la ganadería en Latinoamérica. Livest. Res. Rural Dev. 13(3). Disponível em <http://www.lrrd.org/lrrd13/3/murg133.htm> Acesso em 31 jul. 2013.

Nickerson S.C. \& Philpot N. 2000. Wining the Fight Against the Mastitis. Westfalia Surge, Philadelphia. 295p.

National Mastitis Council (NMC). 1987. Current Concepts of Bovine Mastitis, $3^{\text {rd }}$ ed. NMC, Madison. 33p.

OIE 2013. OIE member countries's official FMD status map. Disponível em <http://www.oie.int/en/animal-health-in-the-world/official-disease-status/fmd/en-fmd-carte/> Acesso em 12 Jan. 2013.

Pagano M. \& Gauvreau K. 2003. Princípios de Bioestatística. Thomson Learning, São Paulo. 522p.

Philips C.J. \& Sorensen J.T. 1993. Sustainability in cattle production systems. J. Agric. Environ. Ethics 6:61-73.

Quinn P.J., Markey B.K., Leonard F.C., FitzPatrick E.S., Fanning S. \& Hartigan P.J. 2011. Veterinary Microbiology and Microbial Diseases. $2^{\text {nd }}$ ed. Blackwell Science, Oxford, UK. 1243p.

Radostits O.M., Gay C.C., Hinchcliff K.W. \& Constable P.D. 2007. Veterinary Medicine: a textbook of the disease of cattle, horses, sheep, pigs and goats. Saunders Elsevier, Philadelphia. 2156p.

Ribeiro M.G. 2008. Princípios terapêuticos na mastite em animais de produção e de companhia, p.759-771. In: Andrade S.F. (Ed.). Manual de Terapêutica Veterinária. $3^{\mathrm{a}}$ ed. Roca, São Paulo.

Ribeiro M.G., Geraldo J.S., Langoni H., Lara G.H.B., Siqueira A.K., Salerno T. \& Fernandes M.C. 2009. Microrganismos patogênicos, celularidade, e resíduos de antimicrobianos no leite bovino produzido no sistema orgânico. Pesq. Vet. Bras. 29:52-58.

Roesch M., Doherr G., Schären W., Schällibaum M. \& Blum J.W. 2007. Subclinical mastitis in dairy cows in Swiss organic and conventional production systems. J. Dairy Res. 74:86-92.

Santos M.V. \& Fonseca L.F.L. 2007. Estratégias para Controle de Mastite e Melhoria da Qualidade do Leite. Manole, Barueri. 314p.

Schalm O.W., Carrol E.J. \& Jain N.C. 1971. Bovine Mastitis. Lea and Febiger, Philadelphia. 360p.

Singh H. \& Bennett R.J. 2002. Milk and milk processing, p.1-11. In: Robinson R.K. (Ed.), Dairy Microbiology Handbook. John Wiley and Sons, New York.

Smith K L. 1996. Standards for somatic cells in milk: physiological and regulatory. IDF Mastitis Newsletter 21:7-9.

Tinoco-Magaña J.F., Aguilar-Pérez C.F., Delgado-León R., Magaña-Monforte J.G., Ku-Vera J.C. \& Herrera-Camacho J. 2012. Effects of energy suplementation on productivity dual-purpose cows grazing in a silvopastoral system in the tropics. Trop. Anim. Health Prod. 44:1073-1078.

Trabulsi L.R., Alterthun F., Gompertz O.F. \& Candeias J.A.N. 1999. Microbio$\operatorname{logia} .3^{\mathrm{a}}$ ed. Atheneu, São Paulo. 586p.

Trujillo C.M., Gallego A.F., Ramírez N. \& Palacio L.G. 2010. Prevalence of mastitis in dairy herds in Eastern Antioquia. Revta Colomb. Cienc. Pec. 24:11-18.

Urbano D., Dávila C., Cañas H., Castro F. \& Moreno P. 2006. Comparación del sistema silvopastoril y gramínea sobre la producción y calidad de leche en vacas criollo limonero. Disponível em <http://www.calidad. com.mx/docs/art_31_32.pdf> Acessado em 31 jul. 2013. 